\section{- OPEN ACCESS}

\title{
Gemcitabine-induced chronic systemic capillary leak syndrome
}

\author{
Ravneet Bajwa, Jason Starr, Karen Daily
}

Division of Hematology and Oncology, College of Medicine, University of Florida, Gainesville, Florida, USA

\section{Correspondence to Dr Ravneet Bajwa, ravneet.bajwa@medicine.ufl.edu}

Accepted 16 August 2017

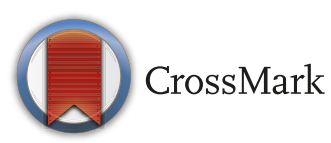

To cite: Bajwa R, Starr J, Daily K. BMJ Case Rep Published Online First: [please include Day Month Year]. doi:10.1136/bcr-2017 221068

\begin{abstract}
SUMMARY
A 56-year-old woman presented with anasarca, hypoalbuminaemia and hypotension following cycle 3 day 1 of adjuvant gemcitabine for stage II pancreatic cancer. Due to the temporal nature of presentation, suspicion for gemcitabine-induced capillary leak syndrome was included in the differential diagnosis. Vascular endothelial growth factor levels were elevated at $707 \mathrm{pg} / \mathrm{mL}$ (reference range: 9-86 pg/mL). Corticosteroids were initiated, resulting in complete resolution of symptoms and hypotension. The patient suffered relapse of symptoms on discontinuation of steroids, further supporting chronic capillary leak syndrome.
\end{abstract}

\section{BACKGROUND}

Systemic capillary leak syndrome (SCLS) is a rare disorder characterised by hypotension, hypoalbuminaemia and haemoconcentration. It can be idiopathic (Clarkson's disease) or secondary to various conditions, such as monoclonal gammopathy of undetermined significance, engraftment syndrome after haematopoietic stem cell transplantation, viral infections (eg, viral haemorrhagic fever like hantavirus, dengue haemorrhagic fever), snake bites and secondary to treatments, such as chemotherapy medications. ${ }^{12}$ The pathophysiology is thought to be secondary to derangements in the endothelial surface causing leakage of proteins and plasma into the interstitial compartment. High levels of plasma vascular endothelial growth factor (VEGF) levels have been reported during acute, severe episodes. ${ }^{2}$ Further, elevated levels of VEGF were noted in a series of 23 patients and in several smaller reports. ${ }^{23}$ A chronic form of SCLS has also been described, in which patients present with persistent, non-cyclical, progressive generalised oedema rather than acute attacks and may also have associated pleural and pericardial effusions. ${ }^{4}$ SCLS has been reported as a rare adverse effect from gemcitabine. ${ }^{56}$ The exact pathophysiology of gemcitabine-induced capillary leak syndrome is unclear.

\section{CASE PRESENTATION}

We present here a case of a 56-year-old woman who was diagnosed with stage IIB (pT3pN1M0), moderately differentiated adenocarcinoma of the pancreatic head. In September 2015, the patient underwent a pancreatojejunostomy (Whipple procedure) with resection of a long afferent limb from a previous gastric bypass and placement of a feeding jejunostomy for enteral nutrition. This was followed by adjuvant radiation (50.4 Gy at $1.8 \mathrm{~Gy} /$ fraction) to the pancreatic tumour bed with concurrent continuous infusion of 5 -fluorouracil. Subsequently the patient began adjuvant gemcitabine $\left(1000 \mathrm{mg} / \mathrm{m}^{2}\right)$ on days 1,8 and 15 of each 28 day cycle. She received cycle 3 , day 1 of gemcitabine in April 2016 and presented to the emergency room (ER) 10 days later with complaints of worsening shortness of breath. Evaluation revealed the patient to have anasarca, bilateral pleural effusions and hypotension (systolic blood pressure ranging from 77 to $87 \mathrm{~mm} \mathrm{Hg}$ ). The patient reported previous episodes of hypotension and oedema with gemcitabine infusions, managed with intravenous fluids in the chemotherapy infusion room and ER.

Her other medical history included hypertension, pancreatitis, gastro-oesophageal reflux disease with Barrett's oesophagus and insulin dependent diabetes mellitus. Her surgical history included laparoscopic Roux-en-Y gastric bypass, cholecystectomy and total abdominal hysterectomy with salpingo-oophorectomy. She had prior alcohol abuse and a 60-pack year smoking history.

\section{INVESTIGATIONS}

Laboratory evaluation at the time of hospitalisation described aboverevealed profound hypoalbuminaemia with albumin level of $1.8 \mathrm{~g} / \mathrm{dL}$ (reference range: $3.5-5.0 \mathrm{~g} / \mathrm{dL}$ ) and total protein of $4.6 \mathrm{~g} / \mathrm{dL}$ (reference range: $6.4-8.3 \mathrm{~g} / \mathrm{dL}$ ). Complete blood count revealed haematocrit 32\%. B-natriuretic peptide prior to starting gemcitabine was $361 \mathrm{pg} / \mathrm{mL}$ (reference range: $<125 \mathrm{pg} / \mathrm{mL}$ ). During this hospitalisation, it was $366 \mathrm{pg} / \mathrm{mL}$. Cortisol (drawn the morning following the day of admission) was noted to be $12.7 \mathrm{mcg} / \mathrm{dL}$ (reference range: AM $7.0-22.0 \mathrm{mcg} / \mathrm{dL}$, PM $3.0-9.0 \mathrm{mcg} / \mathrm{dL}$ ). Urinalysis was negative for any proteinuria.

CT scan of the chest, abdomen and pelvis did not show recurrence of cancer but was significant for bilateral pleural effusions and extensive hepatic steatosis with diffuse soft tissue anasarca and simple ascites.

An echocardiogram on admission revealed an ejection fraction (EF) of $65 \%$. Similarly, an echocardiogram done before initiation of gemcitabine revealed an EF of $65 \%$.

\section{DIFFERENTIAL DIAGNOSIS}

SCLS is under-recognised due to its rarity and non-specific presenting symptoms. Many patients 
presenting with hypotension are presumed to have septic shock and are treated with antibiotics and intravenous fluids. ${ }^{7}$ Unlike the hypotension associated with anaphylaxis, which usually resolves with administration of subcutaneous epinephrine, the hypotension in SCLS can be resistant to medications including vasopressors.

Congestive heart failure and nephrotic syndrome can present with anasarca but have associated findings of poor EF on echocardiogram and proteinuria on urinalysis, respectively. Our patient had a normal echocardiogram and urinalysis.

Adrenal insufficiency can also mimic SCLS with hypotension, diarrhoea and hypoalbuminaemia. Cortisol levels are typically low in these patients. Cortisol levels in our patient were normal on two separate occasions.

Pancreatic insufficiency secondary to pancreas surgery can lead to malabsorption and subsequent hypoalbuminaemia with resultant oedema. This is typically associated with diarrhoea and steatorrhoea, which our patient did not have. Further, our patient was on postoperative supplemental pancreatic enzymes.

Hereditary angioedema typically presents in adults with recurrent attacks of cutaneous and gastrointestinal oedema. It is due to deficiency or dysfunction of C1 inhibitor. Unlike the generalised oedema of SCLS, the cutaneous swelling of hereditary angioedema is usually localised.

Toxic shock syndrome presents with high fever, hypotension and rash. The presence of skin findings along with infection source and/or blood cultures will help distinguish toxic shock syndrome from SCLS.

Gleich syndrome is characterised by recurrent episodes of angioedema, urticaria, pruritus, fever, weight gain, oliguria and eosinophilia. Symptoms occur in cycles of 3-4 weeks and resolve spontaneously. Our patient did not exhibit features of this disease.

\section{TREATMENT}

Initial evaluation for an infectious aetiology was negative. The patient received several doses of intravenous albumin $25 \mathrm{~g}$ along with midodrine. Despite escalating doses of midodrine, the patient continued to have refractory hypotension, requiring intravenous fluid boluses.

On further review of the patient's history and records, the episodes of hypotension appeared to be temporally linked to the infusions of gemcitabine. When the patient did not respond to midodrine, we considered the diagnosis of capillary leak syndrome induced by gemcitabine. The patient was started on methylprednisolone $(1 \mathrm{mg} / \mathrm{kg})$, and VEGF levels from peripheral blood were sent. The patient responded quickly to treatment with resolution of hypotensive episodes within 24 hours. The albumin gradually increased to $2.2 \mathrm{~g} / \mathrm{dL}$ over a period of 2 weeks. VEGF levels were elevated at $707 \mathrm{pg} / \mathrm{mL}$ (reference range: $9-86 \mathrm{pg} / \mathrm{mL}$ ). The patient was treated with high-dose steroids prednisone $(1 \mathrm{mg} / \mathrm{kg})$ for a week and then discharged on $10 \mathrm{mg}$ daily. Given the above clinical events gemcitabine was permanently discontinued.

\section{OUTCOME AND FOLLOW-UP}

Unfortunately, the patient stopped taking steroids against medical advice and presented to the hospital with similar complaints approximately 2 months later. It was unclear why the patient discontinued the steroids. A complete workup to rule out other causes of SCLS was performed during the hospitalisation, which included serum protein electrophoresis (SPEP) with immunofixation, quantitative immunoglobulins, kappa/lambda free light chains, serum cortisol and antiphospholipid antibody syndrome testing; all which were negative. A repeat echocardiogram showed again an EF of $65 \%$. Laboratories revealed total protein of $5.5 \mathrm{~g} / \mathrm{dL}$, albumin $1.6 \mathrm{~g} / \mathrm{dL}$. Haematocrit was $41 \%$. Urinalysis revealed trace $(30-50 \mathrm{mg} / \mathrm{dL})$ proteinuria. Given the multiple hospitalisations and the patient's general decline in health, she opted to forego all treatment, including corticosteroids and pursued hospice care. She passed away shortly thereafter. An autopsy was not performed.

\section{DISCUSSION}

SCLS is a rare and potentially fatal disorder characterised by recurrent episodes of generalised oedema, haemoconcentration and severe hypotension. Dr Clarkson first described it in 1960 and since then both case reports and case series have been published in literature. ${ }^{17}$ The exact incidence of the disorder is unknown as most cases go undiagnosed. The incidence seems to have increased in the past 15 years, due to increased awareness and successful identification of the disease with the help of classic laboratory findings. ${ }^{8}$

Most patients present with a prodrome of fatigue, abdominal pain, nausea, myalgias, polydipsia and sudden increase in body weight. Episodes of hypotension presenting as lightheadedness and dizziness are common. The hypotension usually lasts for several days accompanied by massive extravasation of fluid resulting in oedema and anasarca. During quiescent periods between attacks, patients are usually asymptomatic.

Acute attacks are characterised by elevation in haematocrit concentration. The median absolute increase in haematocrit in a retrospective review was seen to be about $19.8 \% .^{8}$ Hypoalbuminaemia is another classic feature of the disease. Presence of a monoclonal protein, usually IgG kappa, is seen in about $80 \%$ of patients. This is the only laboratory abnormality which will persist in the quiescent phase of the disease. ${ }^{4} 8$ Antiphospholipid antibodies as aetiology for SCLS have been reported in case reports. $^{9}$

The pathogenesis of the disease remains unclear, but vascular endothelial growth factor, cytokines and complements have been implicated. Whether the monoclonal paraproteins present in SCLS contribute directly to disease pathogenesis is unclear.

In patients with the chronic form of capillary leak syndrome, there are often pleural and pericardial effusions, as seen in our patient. ${ }^{47}$ Chronic capillary leak syndrome induced by gemcitabine has been reported previously in case reports and may respond to a therapeutic regimen of prednisone, furosemide and theophylline. ${ }^{7}$

Gemcitabine is an $\mathrm{S}$ phase specific pyrimidine antimetabolite which impairs DNA synthesis by competitively inhibiting DNA polymerase and gets incorporated in DNA leading to impaired chain elongation. ${ }^{10}$ Gemcitabine is typically well tolerated and is used in a number of different malignancies including: pancreaticobiliary, bladder, non-small cell lung, Hodgkin lymphoma, breast, ovarian and testicular cancers. Neutropaenia and thrombocytopaenia can be dose limiting. Other adverse effects include transaminitis, peripheral oedema and fever.

The pathophysiology of capillary leak syndrome induced by gemcitabine is unknown. It is hypothesised that this syndrome occurs along the spectrum with gemcitabine pulmonary toxicity (GPT). GPT is thought to be secondary to endothelial dysfunction subsequently causing capillary leakage. ${ }^{11-13}$ The incidence of gemcitabine-induced SCLS is unknown, but the overall incidence of GPT is less than $1 \% .{ }^{12}$ Increasing peripheral oedema along with decreasing serum albumin in patients receiving 
gemcitabine should prompt the clinician to SCLS. Patients with gemcitabine-induced SCLS and/or GPT typically respond to systemic steroids. ${ }^{511} 14$ Cessation of gemcitabine is mandatory.

Our patient's episodes were closely linked to gemcitabine infusions and there was resolution of symptoms with the addition of steroids. Relapse of disease with the discontinuation of steroids likely reflected chronic capillary leak syndrome which is known to have a relapsing and remitting course. Our patient's albumin had decreased after the Whipple procedure $(2.4-2.7 \mathrm{~g} /$ $\mathrm{dL}$ ) and prior to starting gemcitabine which likely reflected a nutritional deficiency. However, after starting gemcitabine, her albumin decreased to as low as $1.3 \mathrm{~g} / \mathrm{dL}$. The rapid response of albumin and her episodes of hypotension to steroids favours capillary leak syndrome as the aetiology of her symptoms and clinical findings.

\section{Learning points}

- Systemic capillary leak syndrome (SCLS) is a rare disorder which is often missed at the initial diagnosis due to non-specific symptoms leading to high mortality.

- Triad of hypotension, oedema and elevated haematocrit should alert the physician to a possible diagnosis of acute systemic SCLC.

- Although the aetiology is not well understood, SCLC is thought to be secondary to vascular endothelial damage. Elevated levels of vascular endothelial growth factors are commonly reported in the literature.

- Gemcitabine-induced capillary leak syndrome is a rare, potentially lethal side effect of gemcitabine. Death can ensue if there is a delay in this diagnosis and thus SCLS should be kept in the differential diagnosis in a patient with unremitting oedema and hypotension.

Contributors RB contributed to writing and drafting the case report, gathering all information and getting informed consent from the patient's family. KD and JS provided critical revisions and added intellectual content.

Competing interests None declared.
Patient consent Obtained from guardian.

Provenance and peer review Not commissioned; externally peer reviewed.

Open Access This is an Open Access article distributed in accordance with the Creative Commons Attribution Non Commercial (CC BY-NC 4.0) license, which permits others to distribute, remix, adapt, build upon this work non-commercially, and license their derivative works on different terms, provided the original work is properly cited and the use is non-commercial. See: http://creativecommons.org/ licenses/by-nc/4.0/

(C) BMJ Publishing Group Ltd (unless otherwise stated in the text of the article) 2017. All rights reserved. No commercial use is permitted unless otherwise expressly granted.

\section{REFERENCES}

1 Duron L, Delestre F, Amoura Z, et al. Idiopathic and secondary capillary leak syndromes: a systematic review of the literature. Rev Med Interne 2015;36:386-94.

2 Lesterhuis WJ, Rennings AJ, Leenders WP, et al. Vascular endothelial growth factor in systemic capillary leak syndrome. Am J Med 2009;122:e5-e7.

3 Xie Z, Ghosh CC, Patel R, et al. Vascular endothelial hyperpermeability induces the clinical symptoms of Clarkson disease (the systemic capillary leak syndrome). Blood 2012;119:4321-32.

4 Druey KM, Greipp PR. Narrative review: the systemic capillary leak syndrome. Ann Intern Med 2010;153:90-8.

5 Biswas S, Nik S, Corrie PG. Severe gemcitabine-induced capillary-leak syndrome mimicking cardiac failure in a patient with advanced pancreatic cancer and high-risk cardiovascular disease. Clin Oncol 2004;16:577-9.

6 Baron D, Mayo A, Kluger Y. Gemcitabine-induced chronic systemic capillary leak syndrome: a life-threatening disease. Clin Oncol 2006;18:90-1.

7 Airaghi L, Montori D, Santambrogio L, et al. Chronic systemic capillary leak syndrome. Report of a case and review of the literature. J Intern Med 2000;247:731-5.

8 Kapoor P, Greipp PT, Schaefer EW, et al. Idiopathic systemic capillary leak syndrome (Clarkson's disease): the Mayo clinic experience. Mayo Clin Proc 2010;85:905-12.

9 Prete M, Urso L, Fatone MC, et al. Antiphospholipids syndrome complicated by a systemic capillary leak-like syndrome treated with steroids and intravenous immunoglobulins: a case report. Medicine 2016;95:e2648.

10 Plunkett W, Huang P, Searcy CE, et al. Gemcitabine: preclinical pharmacology and mechanisms of action. Semin Oncol 1996;23:3-15.

11 Pavlakis N, Bell DR, Millward MJ, et al. Fatal pulmonary toxicity resulting from treatment with gemcitabine. Cancer 1997;80:286-91.

12 Barlesi F, Villani P, Doddoli C, et al. Gemcitabine-induced severe pulmonary toxicity. Fundam Clin Pharmacol 2004;18:85-91.

13 Gupta N, Ahmed I, Steinberg H, et al. Gemcitabine-induced pulmonary toxicity: case report and review of the literature. Am J Clin Oncol 2002;25:96-100.

14 Vander Els NJ, Miller V. Successful treatment of gemcitabine toxicity with a brief course of oral corticosteroid therapy. Chest 1998;114:1779-81.

Copyright 2017 BMJ Publishing Group. All rights reserved. For permission to reuse any of this content visit

http://group.bmj.com/group/rights-licensing/permissions.

BMJ Case Report Fellows may re-use this article for personal use and teaching without any further permission.

Become a Fellow of BMJ Case Reports today and you can:

- Submit as many cases as you like

- Enjoy fast sympathetic peer review and rapid publication of accepted articles

- Access all the published articles

- Re-use any of the published material for personal use and teaching without further permission

For information on Institutional Fellowships contact consortiasales@bmjgroup.com

Visit casereports.bmj.com for more articles like this and to become a Fellow 